\title{
1 \\ The Declaration on the Rights of Indigenous Peoples
}

[There is a] profound question of whether a State built upon the taking of another people's lands, lives and power can ever really be just. (Matike Mai Aotearoa, 2016, p. 29)

\section{Introduction}

It may be true that a state built on taking another's lands can never be just. Neither constitutions nor politics can guarantee that justice has pervasive influence. Yet injustice may be mitigated, and there may be broad principles of justice to inform the development of nondominant and noncolonial political relationships that are, pragmatically, worth indigenous people pursuing. Such principles are imbued in the Declaration-an instrument that takes international human rights discourse beyond the individual to the collective. The Declaration's 'essential novelty' (Wiessner, 2009, p. 4) is that it makes collective rights 'indispensable' (p. 41) and an essential consideration for indigenous political capacity. It therefore shows why it is unjust to think about indigenous rights as simply a subset of general ethnic minority rights. The conflation of indigenous claims with those of migrant ethnic minority populations undermines the right to self-determination. It overlooks the distinctiveness of indigenous claims, including that their source is in relation to land and culture. They may be shaped by colonial histories and political disadvantage and may be compounded by minority population status, but these are not indigeneity's defining characteristics. 
The Declaration enunciates political capacities belonging to indigenous nations that are grounded in prior occupancy. Relationships to defined territories thus provide an important distinction with the rights of minorities, and, as this book explains, just terms of association require careful attention to those contexts.

The Declaration precludes an exclusive state sovereignty and gives specific context to general principles of non-discrimination. It requires reimagining the liberal state's form and character and the ways that it manages political relationships. In showing that democratic exclusion is not liberalism's inevitable or necessary form, the Declaration responds to the maldistribution of political authority rather than simply the egalitarian concerns of the indigenous poor.

The Declaration imagines forms of self-determination grounded in substantive indigenous agency-the political capacity to realise rights grounded in prior occupancy. However, its enduring value, like that of the Treaty of Waitangi in New Zealand, is its capacity to support just terms of association between indigenous nations and the liberal state. It supports these terms of association by acknowledging that indigenous peoples rightly exercise the capacities of citizenship as indigenous. This could mean having a distinctive voice within the political system, the right to learn at school in cultural context or to influence the provision of health services with reference to cultural imperatives, among other such rights.

This chapter argues that the Declaration's value in contemporary liberal states, like those that dissented from the Declaration's adoption, lies not only in its challenge to prevailing political values and institutions but also, and ultimately, in its potential to remake public institutions in ways that create scope for substantive indigenous agency. The limits and moral shortcomings of the Declaration are examined from both state and indigenous perspectives in later chapters. This chapter's purpose is to introduce the possibilities that the Declaration raises for a more inclusive state. Those possibilities are usefully assessed in relation to a liberal theory of indigeneity that finds practical expression in differentiated liberal citizenship. A liberal theory of indigeneity may, if societies wish, provide ways of thinking inclusively about citizenship, sovereignty and democracy. One of this book's recurring observations is that reconsidering these concepts allows indigenous politics to think beyond an exclusive non-indigenous state or Crown as the sole or inevitable repository of public authority. 


\section{Indigenous Peoples and the Liberal Paradigm}

Moreton-Robinson (2003, 2004) and Watson and Venne (2012) have shown why indigenous peoples do not routinely look to the liberal paradigm to address collective claims. However, a distinctive liberal theory of indigeneity can be read into the Declaration. That theory shows that the restrictive practices that these Indigenous Australian scholars identify are not essential to liberal philosophy. They are practices that can be challenged to provide a philosophical path beyond the 'framework of liberal individualism versus corporatism' (Holder \& Corntassel, 2002, p. 127): a framework that limits indigenous peoples' full enjoyment of their universal human rights as indigenous peoples. It is at least partly to these ends that the Declaration sets out new possibilities for relational justice. For example, the Canadian Assembly of First Nations (2017) pursued relational justice with the state by establishing principles to guide political relationships and by providing 'ways to measure and assess [how] states are respecting and implementing the rights of indigenous peoples' (para. 1). The reports of UN special rapporteurs on the rights of indigenous peoples, and country and nongovernment organisation reports to UN bodies, such as the Committee on the Elimination of Racial Discrimination, inform such efforts, which may, over time, enable the Declaration to acquire persuasive value in domestic legal proceedings, as discussed in Chapter 3.

Meanwhile, Carroll (2012) has argued that the Declaration 'presented the global state community with a political litmus test that exposed ... the unique relationships between indigenous peoples and the states into which they have found themselves subsumed' (p. 143). Self-determination requires that these unique relationships must be developed to privilege indigenous political agency meaning that, in turn, Holder and Corntassel (2002, p. 141) err in referring to settler states as the 'host states' of indigenous peoples who occupy the same territories. In using the concept of 'host', Holder and Corntassel (2002) position indigenous peoples as the 'other'-as beyond the state and therefore beyond the legal entity whose decisions materially influence their capacities for self-determination. 
The term 'host' implies a voluntarily accepted relationship. One is only 'hosted' if one so chooses. Agency requires a different approach-one of genuine democratic inclusivity broadly accepted by indigenous peoples. It is to support aspirations for democratic inclusivity that one of this book's principal aims is to contest the legitimacy of the idea that:

The formal theory of the unitary and exclusive sovereignty of the Crown-in-Parliament has endured as a vestigial orthodoxy, relatively unperturbed by theories denying the Crown's unitary character or its formal supremacy. (Kingsbury, 2002, p. 119)

In New Zealand, this understanding of sovereignty informs a common Maori acceptance of a Crown-Maori, 'them' and 'us', binary, the implications of which are systematically discussed in Chapter 9 (see also O'Sullivan, 2007). This book draws an alternative and liberal political framework from the Declaration to transcend that binary. It does so by acknowledging that the Declaration provides for more inclusive conceptions of sovereignty, citizenship and democracy, which then makes it realistic to contemplate an alternative view of Crown sovereignty where the Crown is:

an inclusive institution [that] forges a sense of the population as bound together in a common enterprise. The Crown, as a mediating institution, is the addressee of demands and complaints made by different groups, enabling the country to avoid a dangerously ethnicised politics in which Maori and non-Maori confront each other directly and repeatedly. (Kingsbury, 2002, p. 119)

A liberal theory of indigeneity is a theory of autonomy, but as a theory concerned with democratic inclusivity, it also aims to minimise the circumstances under which confrontation is likely to occur. It describes the conditions under which indigenous peoples might acquire maximum independence and authority within the state, while retaining the attributes of independent authority in and over their own affairs. Citizenship must then be understood as embodying a set of political capacities that belong not just to individuals but also to indigenous nations. A liberal theory of indigeneity is concerned with the state's political character. This is a wider and deeper concern than governments simply acting fairly or determining a 'special duty' owed to indigenous people. Rather, it describes the political conditions under which indigenous peoples might do justice to themselves, thereby securing what they owe to themselves as indigenous citizens of an inclusive liberal society. This is important because it provides 
an indigenous political theory responsive to Benhabib's (1996) questions about democracy's character and what that character might mean for indigenous self-determination:

Does democracy rest on homogenising models of identity? What does the body of the 'body politic' look like? Can the ideal of universal citizenship accommodate difference? What institutional, cultural, and representational channels are there for the expression of difference? How much difference is compatible with the ideal of the rule of law under fair and equal conditions? (p. 5)

This book examines how the Declaration helps to conceptualise a state in which indigenous people have the same capacities as anyone else to influence the values and purposes that public institutions are developed to serve. It contrasts this inclusive ideal with the philosophical objections to a liberal theory of indigeneity that arise from theories of democratic exclusion. Under these theories, homogeneity is privileged as the democratic ideal. Justice is equated with sameness. The presumption is that culture has no place in the public realm and that substantive claims to restitution or recognition may not be justly entertained. If each person's political rights and obligations are the same, then they are recognisable and exercisable only in the same ways. However, the principle of justice through sameness is incomplete if sameness can obstruct fairness.

If public relationships among citizens are fair, differences in context and aspirations will have been taken into account. Personal liberty makes such differences legitimate. The circumstances that distinguish any person's present are shaped by the past: the consequences of the past endure. If the past includes the subjugation of political authority, just relationships do not simply emerge in the present; they can occur only as the product of considered choices about how people belong to the contemporary state. If all are to belong on equal terms, one has to consider the political capacities that allow equality.

The alternative may be that belonging is inextricably tied to white possession' (Moreton-Robinson, 2003, p. 137), which becomes the 'definitive marker of citizenship' (Moreton-Robinson, 2004, p. 79). It is then an oversimplification of indigenous political experience and expectation to argue that:

the general duty of a government to do justice to all people is [not] trumped by any special duty it owes to those of the inhabitants who can claim indigenous descent. (Waldron, 2003, p. 30) 
What is needed is a political order that allows all people to exercise the rights and obligations of humanity in ways that are personally meaningful, an objective that is reflected in the Declaration itself:

1. Indigenous individuals and peoples have the right to enjoy fully all rights established under applicable international and domestic labour law.

2. States shall in consultation and cooperation with indigenous peoples take specific measures to protect indigenous children from economic exploitation and from performing any work that is likely to be hazardous or to interfere with the child's education, or to be harmful to the child's health or physical, mental, spiritual, moral or social development, taking into account their special vulnerability and the importance of education for their empowerment.

3. Indigenous individuals have the right not to be subjected to any discriminatory conditions of labour and, inter alia, employment or salary. (UN, 2007b, art. 17)

In Australia, for example, respect for these human rights would have prevented policies separating Indigenous children from their families, prevented land alienation, ensured education and health care equivalent to that available to other members of the community, prevented discrimination in criminal justice and the labour market, precluded the closure of remote Indigenous communities, prevented the Western Australian Government's refusal to engage with Indigenous communities in reaching policy decisions in this context and made the Northern Territory Emergency Response ('the Intervention') impossible. ${ }^{1}$ Instead, and as subsequent chapters discuss, the Declaration supports an indigenous political focus on good health, education, housing, employment and land rights; affirms the negotiation of treaties to mark formal recognition of indigenous people's prior occupancy; and shows how human rights may have prevented colonisation, a process that undermines the political rights of all indigenous people, not just the material claims of the indigenous poor.

1 The Intervention was an 'emergency' policy response to alleged widespread sexual abuse of children in the Northern Territory, Australia, in 2007. There was no indigenous participation in developing the policy response, which required the suspension of the Commonwealth Racial Discrimination Act 1975. 
Prioritising concern for the indigenous poor reflects a kind of distributive justice that separates individual liberty from the cultural contexts and collective environments in which people actually live. Material disadvantage is a public policy outcome; it is not in itself the source of indigenous claims. Indigenous people might be interested in class politics, but indigeneity is a different politics concerned with the maldistribution of political authority. Indigenous peoples' conscious democratic exclusion arises from 'institutionalised patterns of cultural value' (Fraser, as cited in Fraser \& Honneth, 2003, p. 30) that are not indigenous and that indigenous people may not have sufficient democratic opportunities to contest.

Exclusion contributes to policy failure (Banks, 2007), which is often explained by a 'power narrative' (Altman, 2009, p. 43) of indigenous inadequacy - specifically, the failings of culture and of personal responsibility. By contrast, democratic inclusion might occur through what Hunt and Blackman (2009) call 'active and informed participation', resulting in both 'non-discrimination' and 'cultural acceptability' in policy outcomes (p. 9). This objective is beyond the concerns of liberal egalitarianism.

\section{Beyond Liberal Egalitarianism}

Liberal egalitarianism is concerned with poverty alleviation through the fair distribution of material resources. However, egalitarian justice is not equipped to consider claims to culture, language, collective resource ownership, substantive political authority or just terms of association. These essential constituents of a liberal theory of indigeneity explain the limits of undifferentiated liberal citizenship. Instead, the Declaration maintains that:

1. Indigenous peoples have the right to practice and revitalize their cultural traditions and customs. This includes the right to maintain, protect and develop the past, present and future manifestations of their cultures, such as archaeological and historical sites, artefacts, designs, ceremonies, technologies and visual and performing arts and literature.

2. States shall provide redress through effective mechanisms, which may include restitution, developed in conjunction with indigenous peoples, with respect to their cultural, intellectual, religious and spiritual property taken without their free, prior and informed consent or in violation of their laws, traditions and customs. (UN, 2007b, art. 11) 
A liberal theory of indigeneity develops these rights not as claims to privilege over others or a 'birthright to the upper hand' (Brash, 2004, para. 7), but as claims to relational justice within the sovereign citizenry. Whatever its form, sovereignty ought to serve all citizens equally, including those for whom an indigenous collective identity is important. It should not 'reproduce a space for politics that is enabled by and rests upon the production, naturalization and maginalization of certain forms of "difference" (Shaw, 2008, p. 9), but should be stable, clear, ordered and obviously inclusive. These are determinants of the political space that is required for the right to self-determination to have practical meaning and improve the lives of indigenous peoples-determinants of a political space where public sovereignty is shared.

Sharing public sovereignty means that public institutions should not be 'theirs', as in an 'us' and 'them' binary, but should reflect all people's right to contribute to the formation of public values and the ways in which public institutions work. If, as Benhabib (1996) argued, the 'claims of culture' are limited by their consistency with prevailing norms and values, then indigenous peoples must enjoy meaningful opportunities to shape those norms and values. This is the assumption of New Zealand's Te Kotahitanga research and professional development program for school teachers (see Chapter 5), which seeks to ensure that Maori achievements at school are not dependent on their putting their own values and ways of life to one side. Te Kotahitanga's underlying pedagogic principle is that Maori should be able to bring their culture into the classroom and that culture should not be an impediment to success (Bishop, O'Sullivan \& Berryman, 2010). This acknowledges the reality that, when people claim membership of a group:

What they are saying ... is not just that they are strongly attached to this spiritual view or background; rather it is that this provides the frame within which they can determine where they stand on questions of what is good. (Taylor, 1989, p. 27)

Culture helps to frame people's expectations of citizenship, including schooling and, more broadly, of what it means to be a free and politically equal person. Given culture's political importance, it is idealistic to argue that, for the resolution of conflict, 'there must be some standard by which to determine the goodness or badness' of competing claims, and that 'whatever that standard is, there can be but one' (Mill, 1843, p. 951). 
Instead, the Declaration provides an international standard for assessing indigenous claims as distinctive claims, and for assessing the counterclaims of the state.

The Declaration precludes indigenous people-and by extension their cultures-from deliberate and systematic exclusion from substantive citizenship. While it does not prescribe the form that indigenous inclusion should take, the presumption that inclusion should always and everywhere occur if that is the indigenous wish is significant.

Admitting indigenous ways of being human into state law complements the native Canadian argument that the Declaration imposes a responsibility to live up to the concept of being a self-determining human ... it is a new way to reform and empower our traditions and versions of humanities' (Henderson, 2017, p. 13).

Self-determination is present when 'responsibility-based' (Corntassel, 2008, p. 123) movements reflect self-determination as a body of political capacities and not simply a body of rights. In this way, self-determination 'de-center[s] the state from discussions of indigenous political, social, economic, and cultural mobilization' (Corntassel, 2008, p. 123). Self-determination is then a reflection of political space; specifically, the space 'to function well if one so chooses' (Nussbaum, 1987, p. 20) and in ways that are personally meaningful. This book shows, in the discussions that follow, that these aspirations are reasonable and realisable because 'discourses of difference ... are part of the liberal tradition' (Little, 2003, p. 25). In particular, indigenous values and political processes should influence the conduct of public affairs.

Rather than be subservient to those of the state, indigenous political philosophies should legitimately influence public affairs so that space is created 'for [indigenous] right[s] to be distinct, on [their] own path, and free from interference' (Garrow, 2012, p. 182). This argument rationalises differentiated liberal citizenship's concern for protecting language and culture in public institutions and in traditional spheres. However, the right to self-determination cannot be limited to matters of culture, for culture is maintained only by economic security and substantive participation at all levels of the political process. Substantive political participation is both 'instrumental and constitutive' (Ruger, 2006, p. 298) of a fair policy process, including economic policies that are conducive to indigenous 
economic security. This is democratically important because 'at the core of the modern liberal democratic project ... [is] the capability of persons to determine and justify their own actions' (Held, 1995, p. 149).

In jurisdictions like Canada and New Zealand, inclusion remains contested. However, in Australia, inclusion is a new and radical proposition. In 2017, the UN special rapporteur criticised the Australian Government's Indigenous Advancement Strategy's shifting of service delivery contracts away from Indigenous providers as well as its reduced budget for Indigenous policy programs (UN, 2017b). The government defended the Indigenous Advancement Strategy (UN, 2017a) even though its own audit office found wider problems remained in its administration. The audit office report provides a brief but instructive insight into the nature of indigenous public policy failure:

The implementation of the Strategy occurred in a short timeframe and this affected the department [of the Prime Minister and Cabinet]'s ability to establish transitional arrangements and structures that focused on prioritising the needs of Indigenous communities. (Australian National Audit Office, 2017, p. 8)

The audit office also found that:

The department's grants administration processes fell short of the standard required to effectively manage a billion dollars of Commonwealth resources. The basis by which projects were recommended to the Minister was not clear and, as a result, limited assurance is available that the projects funded support the department's desired outcomes. Further, the department did not:

- assess applications in a manner that was consistent with the guidelines and the department's public statements;

- meet some of its obligations under the Commonwealth Grants Rules and Guidelines;

- keep records of key decision; or

- establish performance targets for all funded projects. (Australian National Audit Office, 2017, p. 8)

The report showed that the conditions for informed policy could not be presumed:

The performance framework and measures established for the Strategy do not provide sufficient information to make assessments about program performance and progress towards achievement 
of the program outcomes. The monitoring systems inhibit the department's ability to effectively verify, analyse or report on program performance. The department has commenced some evaluations of individual projects delivered under the Strategy but has not planned its evaluation approach after 2016-17. (Australian National Audit Office, 2017, p. 8)

In 2018, the Department of the Prime Minister and Cabinet released an Annual Evaluation Work Plan for the Indigenous Advancement Strategy. Greater attention was to be paid to ensuring indigenous engagement in implementing the strategy and to what was known about what actually works in indigenous policy - there was to be 'a culture of evidence-based thinking and practice' (Commonwealth of Australia, Department of the Prime Minister and Cabinet, 2018a, p. 1).

Implementing a regime in which effective policy is routinely and systematically supported by widely accepted knowledge of what works represents a significant procedural shift in Australian indigenous public policymaking. For example, the causes of preventable premature indigenous deaths are well known and the relative importance of each cause has been identified and provides policy direction in the development of solutions (O'Sullivan, 2015), yet budgetary allocations to supportive measures have been reduced (UN, 2017a).

According to Vos, Barker, Begg, Stanley and Lopez (2009), 11 risk factors explain the life expectancy differential of Australia's Indigenous people: 'tobacco, alcohol, illicit drugs, high body mass, inadequate physical activity, low intake of fruit and vegetables, high blood pressure, high cholesterol, unsafe sex, child sexual abuse and intimate partner violence' (p. 474). Another risk factor, which is consistent with surveys showing that up to 79 per cent of Indigenous Australians have experienced racism in the health system (Paradies, 2006), is people's reluctance to seek medical advice. One South Australian hospital worker told Dwyer et al. (2011) that:

We're seeing people here who actually haven't accessed the system so their cancers are very, very advanced. We've seen [Aboriginal people] who have got... major carcinoma that's disfiguring, just distorting their body shape... so they've obviously been in pain ... for a long time and that suggests to me that... they're reluctant or reticent or unable to access systems for whatever reason. (quotation is as it appears in the source, p. 18) 
One response may be to admit, systematically, that there is a right to $b e$ indigenous when one goes to hospital — to admit that there is a right to culture-which requires indigenous participation in decisions about how health systems operate and who works in them. This is because health outcomes are not the product of clinical competence alone. They are influenced by health workers' philosophical dispositions towards providing equally effective care to indigenous patients (O'Sullivan, 2015). The marked presence of racism in the health system indicates that effective and culturally respectful care is not always the indigenous experience. Efficacious health care may, then, require fundamental political equality.

\section{Towards Political Equality}

The Declaration is not concerned with special rights but with the codification of liberal democratic rights in historical, political and cultural context. It is 'one law for all' grounded in human equality and cognisant of culture's unavoidable centrality to equality. However, the Declaration is not a panacea for achieving just terms of association. Its limits occur because power is not absolute. For example, the Declaration will not absolutely 'assimilate the colonizer into Aboriginal processes of powersharing', as Watson and Venne (2012, p. 89) desire, yet implementing the Declaration does presume meaningful political recognition, especially—and most importantly_of the right to exercise citizenship in a differentiated form. The Declaration makes this possible by establishing that indigenous persons are 'peoples' and thus entitled to collective recognition (UN, 2007b).

The rights that the Declaration enunciates are grounded in internationally established norms of human equality. They give human rights a collective character that challenges their traditional understanding as belonging only to the individual. Inclusive group rights allow indigenous peoples to reconceptualise their view of the contemporary state not as a Leviathan-like entity but as a body structured, in part, on a liberal theory of indigeneity in which all, and not just some, people share sovereign public authority (O’Sullivan, 2014).

In this way, the Declaration raises the aspirations of indigenous peoples and states alike. For example, it represents the international community's rejection of terra nullius, which presumed that indigenous societies 
lacked the institutional, intellectual and social capacity for nationhood. In Australia, this rejection had allowed Justice Brennan to propose, in his Mabov Queensland [No. 2] (1992) judgment, that:

It is contrary both to international standards and to the fundamental values of our common law to entrench a discrimination rule which, because of the supposed position on the scale of social organisation of the Indigenous inhabitants of a said colony, denies them a right to occupy their traditional lands. (para. 42)

The Declaration also rejects the proposition 'that settlers are citizens because they possess what Indians lack: the capacities for rational self-government and legal institutions of private property, both of which define legal personhood' (Dahl, 2016, p. 17). Dahl continued:

Insofar as citizenship is legally 'defined through the natural right to own property' and rests on the self-ownership of the possessive individual, Indians negatively define settler citizenship by representing the negation of the proprietary self in the absence of dominant conceptions of private property. To the extent that American democracy depends on the propertied independence of citizens, the enclosure of land in private property mirrors the enclosure of settler sovereignty, both of which enact the exclusion of Indians from citizenship. In highlighting the constitutive exclusions of settler democracy, Indian nullification operates less as an institutional feature of constitutional design than as a rhetorical mode that captures the foundational division of settler democracy, the structuring of citizenship along a settler-indigene divide. (Dahl, 2016, p. 17)

Its inclusive emphasis means that, even as an aspirational document (as opposed to an instrument of customary international law), the Declaration is politically and morally valuable. As well as challenging state hegemony over indigenous peoples, it challenges state dominance of international relations and reshapes the ways in which one is able to think about the possibilities and scope of international law and politics. As Mazzuoli and Ribeiro (2015) asserted, this is because human rights 'change the hermeneutics of international law' (p. 1713). Taking this argument further, Patton (2005) argued that:

Against the background of a more comprehensive understanding of the nature and effects of colonial administration, reparation might be described simply as an attempt to constitute a moral and political community where before there was none. (p. 265) 
The idea of a 'moral and political community' is differentiated liberal citizenship's ultimate purpose.

Differentiated citizenship is the condition that the Declaration may create- a condition that allows the politics of indigeneity to test the substantive and practical value of the ways in which liberal democracies work. The Declaration is a robust and considered framework for thinking about the character of differentiated citizenship, the political cultures it might require and the values that it might assume.

The Declaration takes the terms of indigenous peoples' relationships with and within states beyond the realm of domestic law. Its principles endure the vicissitudes of domestic politics and prejudices of local laws and public policies. Under international human rights law, states do not have unconstrained authority. State institutions lie between the constraints of domestic politics and international law-they are bodies that sometimes exist in a state of philosophical conflict over the merits of self-determination. In providing a measure for the international evaluation of domestic policy principles, the Declaration provides a way through this conflict.

The Declaration confirmed all indigenous peoples' place in international law. In doing so, it tried to make indigenous peoples 'subjects rather than objects of international law' (Schulte-Tenckhoff, 2012, p. 76). The effect was to reconceptualise debates about the right to self-determination: to whom did it belong, how might it be exercised and why? The Declaration's extension of the right to self-determination to groups as well as individuals is highly significant for indigenous groups because they have the characteristics of peoplehood: common ancestry, common culture and sustained geopolitical attachments to the same place. This allows a people to organise itself politically in subnational forms, as explained in the Declaration:

States shall consult and cooperate in good faith with the indigenous peoples concerned through their own representative institutions in order to obtain their free, prior and informed consent before adopting and implementing legislative or administrative measures that may affect them. (UN, 2007b, art. 19)

The Declaration presumes that indigenous rights proceed from an overarching right to self-determination, belonging equally to men and women (UN, 2007b, art. 44), and 'should be interpreted in accordance 
with the principles of justice, democracy, respect for human rights, equality, non-discrimination, good governance and good faith' (art. 46[3]). It proposes that the specific rights of women are matters of concern for both states and indigenous nations and makes no distinction between people residing within tribal boundaries and diaspora populations. The right to self-determination is held equally by all indigenous people; the right to belong to one's indigenous community privileges culture over blood quantum.

The Declaration seeks to diminish the state's constraining influence by simultaneously strengthening indigenous nations and ensuring substantive indigenous inclusion in the public life of the state. It promotes indigenous political authority beyond the state through indigenous political institutions, which weakens the state by increasing indigenous entities' relative power. Conversely, the Declaration proposes an inclusive democratic state in which indigenous peoples are guaranteed a substantive voice that, though it serves the state's integrative function, is not assimilationist but, rather, balances the state's authority with the explicit expectation that indigenous peoples can enjoy national citizenship in distinctive ways. This has major implications for democracy and the meaning of indigenous belonging to the state.

The Declaration's challenge to liberal theories of 'belonging' is a 'serious conceptual one' (Gover, 2015, p. 349). It allows indigenous peoples to assert a culturally contextualised and politically independent belonging to the state. Henderson (2008) described the politics surrounding the Declaration as:

a cognitive struggle, a challenge to existing ways of thinking about humanity. It was a manifestation of shared persuasion [emphasis added]. The new emergent consciousness displaces the old discriminatory models of imperialism and colonialism based on racism. (p. 10)

Though nonbinding, the Declaration is a document of 'considerable moral import' (Belanger, 2010, p. 2). Binding status may eventually be acquired through its persuasive legal influence and practical influence as an instrument for public advocacy (Wiessner, 2009). In the meantime, the politics that might be drawn from it should be understood as significant rather than revolutionary-a politics responding to a 'distinctive settler-state political theory' that 'usefully show[s] where existing liberal democratic theories, including those underpinning human rights 
frameworks, "run out" and must be adapted to the particular circumstances of settler societies' (Gover, 2015, p. 348). The Declaration shows how such adaptation is possible and why it contributes to an indigenous politics of liberal possibility and indigeneity. According to Anaya (2010):

the Declaration has a significant normative weight grounded in its high degree of legitimacy ... a function not only of not only the fact that it has been formally endorsed by an overwhelming majority of UN Member States, but also the fact that it is the product of years of advocacy and struggle by indigenous peoples themselves ... The norms of the Declaration substantially reflect indigenous peoples' own aspirations, which after years of deliberation have come to be accepted by the international community. (para. 5)

\section{Liberal Inclusivity}

Rawls (1999) has argued that a complete 'conception of justice' is one that is 'able to order all the claims that can arise' (p. 115). However, it is often a self-serving desire to exclude based on the presumption of inherent superiority that encourages non-indigenous people to imagine that indigenous claims might affront what they are themselves owed in justice. For indigenous peoples, the state is an imposed institution of extraordinary coercive power. It is real, omnipresent and constraining. However, it is not fixed or constant in the functions it maintains nor in its distribution of power; it need not perpetually include or exclude the same people. Liberal theory can, but need not, assume that a majority is always and everywhere 'more likely to be substantively right than a minority' (Mansbridge, 1996, p. 57).

Liberal theory accepts that a decision is neither just nor efficacious simply because it is the majority position. The political process is not an end in itself, for its underlying values influence the fairness of its outcomes. The Declaration presumes that the state must include indigenous peoples who will, as a matter of course, influence the terms of their inclusion. Further, the Declaration recognises and affirms that:

indigenous individuals are entitled without discrimination to all human rights recognized in international law, and that indigenous peoples possess collective rights which are indispensable for their existence, well-being and integral development as peoples. (UN, 2007b, annex) 
The Declaration assumes that liberal democracy can provide a political framework responsive to indigenous needs, rights and aspirations including, especially, a broad and comprehensive right to self-determination. From this perspective, the state need not be a 'message of domination-an ideological artefact attributing unity, structure, and independence to the disunited, structureless and dependent workings of the practice of government' (Abrams, 2006, p. 97). Instead, the state's coercive capacity may be directed towards indigenous good. The state can sometimes rise above the constraints that popular prejudice might otherwise impose. For example, while there is deep-seated public prejudice against settlements for Crown breaches of the Treaty of Waitangi and against the treaty's policy influence, sustained leadership from both sides of the New Zealand Parliament has moderated this resistance.

In New Zealand today, it is unlikely that treaty settlements and guaranteed Maori seats in parliament would receive support in a popular vote. Similarly, Canada's TRC, and Australia's Human Rights and Equal Opportunity Commission's National Inquiry into the Separation of Aboriginal and Torres Strait Islander Children from Their Families, would not have occurred without the state confronting popular prejudice. However, these examples do not diminish the case for a more transformative politics to give postsettler states a secure and inclusive structure that recognises that indigenous peoples are entitled to occupy distinct political spaces within the liberal state. The claim of Indigenous Australians to a constitutionally guaranteed voice in the Australian Parliament is an example, as are claims in New Zealand for better protected independent institutions of Maori political authority. These are discussed in later chapters. In both cases, the possibility of success is enhanced if the proposals are shown as having a liberal justification and the potential to make democracy work better. However, as is also explored in later chapters, making democracy work better is not always an indigenous objective, and other kinds of political relationships may be understood as more consistent with the right to self-determination.

Nevertheless, the Declaration itself presumes that self-determination through differentiated liberal citizenship ought to be structured into domestic political arrangements. This presumption has significant transformative potential. Juxtaposing liberal and indigenous political theories establishes differentiated citizenship as the source of a political language for thinking about and responding to indigenous claims. 
The Declaration provides a comprehensive body of political principles to assist in the development and usefulness of that language- a standard of justice against which institutional arrangements can be measured.

The Declaration also provides a set of principles through which a postcolonial politics might recognise that 'Our children should have the opportunity to live more Indigenous lives than we do' (Alfred, as cited in Corntassel, 2012, p. 99). The purpose is to ensure that the indigenous affairs narrative is not one of victimhood, but one that promotes people living in self-defined equality and dignity. In this regard, the 'hard issue' the Declaration may help to address is 'how to articulate local ideas of peoplehoods, on the one hand, with regional or nationwide ideas about citizenship, on the other' (Bowen, 2000, p. 13). The Declaration addresses this issue by showing the depth of liberal democracy's capacity for differentiated inclusion, thereby allowing the expression of civic rights and responsibilities in a culturally preferred manner. Its point of distinction is that it can acknowledge distinctive indigenous participation in public affairs without restricting the liberal rights of others.

The Declaration assists the politics of indigeneity to work out ways of creating 'legitimate authorities—sovereignties—within and across spatial, temporal and discursive conditions that may be at odds with those that have enabled modern state sovereignty' (Shaw, 2008, p. 5). This means that the state alone is precluded from defining political agendas and entitlements. Instead, meaningful public sovereignty is inclusive, contestable and responsive to the geopolitically contextualised experiences of peoples who did not freely agree to the transfer of political authority to settler states. It is responsive to collective rights as constituents of personal liberty.

However, liberal democracy, as it prevails in Australia, Canada, New Zealand and the US, can struggle to see relationships between collective rights and individual liberty - that is, between sociopolitical experience and personal freedom. Liberal democracies can also find it philosophically difficult to acknowledge culture's place in shaping people's experience of liberty: where, how and why liberty exists, and where, how and why it is constrained.

Liberal democracy may not easily admit that liberty makes sense only in cultural context and for culturally framed reasons. However, the Declaration's liberalism is an inclusive one that positions the individual 
as a bearer of substantive political rights and obligations in common with others. It places the individual in cultural context and gives effect to relationships between personal liberty and the cultural context in which liberty may be defined. Its purpose is to reconfigure the state to ensure that indigenous peoples are part of it, if they wish, and may influence its values, purpose and form.

The political objective is to transform the postsettler states in which indigenous peoples reside such that they lose their colonial character. The presumption is that all people have the right to participate in their government. The state ought not be perpetually the domain of nonindigenous citizens, with indigenous citizens relegated to a less influential indigenous domain. The Declaration's liberal potential is to 'undercut government attempts to assert the moral high ground' and presume 'coercive paternalism' (Dorfmann, 2015, p. 13).

The Declaration provides the liberal political language for indigenous peoples to express their aspirations in ways that are recognisable by the state and consistent with international legal principles. In this way, the Declaration facilitates public reason as an expression of equal capacity for citizenship (discussed in further detail in Chapter 6). The Declaration's liberalism-its assumption that liberty belongs to all and not just some people and that liberty is realised through both collective and individual human rights-is its distinguishing pragmatic value. By such means, it provides a conceptual and practical framework for developing a liberal theory of indigeneity in which indigenous people actively participate in determining the form and purpose of the state.

The Declaration codifies state obligations across policy domains. However, its most important contribution to domestic politics is that it brings philosophical certainty to the question of what it means for an indigenous person to belong to the nation-state. It seeks to ensure that power is distributed in ways that allow the state to become a site in which indigenous self-determination can substantively and systematically displace colonial political relationships. To achieve this, it sets out the attributes of indigenous political authority and its relationships with broader public sovereignty and shows the ways in which public sovereignty is not an unconstrained authority vested only in a non-indigenous government or Crown. 
The Declaration does not go so far as to prescribe Watson and Venne's (2012) aspiration for a decolonised political order. It cannot override alternative political values, but it may challenge them. It may support Watson and Venne's (2012) argument that:

For a real act of decolonization to occur we need to regain an Aboriginal centre - that is, an Aboriginal centre that engages in its own decolonization and repair from the effects of colonialism and to enable that centre to occupy the spaces of political power, rather than let it become assimilated into colonial processes of power-sharing. (pp. 88-89)

As Corntassel (2012) argued, one must be careful not to accept the 'illusion of inclusion' (p. 92) or complacently accept that the Declaration's possibilities will be realised through state benevolence. Just as some policy actors overstate the capacity of New Zealand's Treaty of Waitangi to prescribe processes and outcomes in all areas of public life (O'Sullivan, 2007, 2008), there may be a propensity to expect more from the Declaration than its scope and content allow. It is important that people do not expect that the UN can 'somehow "gift" rights to indigenous peoples': while indigenous rights instead 'inherently flow from customary rights' (Beatty, 2014, p. 49), they must still be actively sought by indigenous peoples who must be clear about what they want and why.

The Declaration pays special attention to state obligations to indigenous citizens. However, it also allows indigenous peoples to make their own claims over and above the nation-state. It provides authoritative guidance to indigenous peoples on how rights might be asserted in both law and politics. Although recourse to international courts, tribunals and committees may not lead to legally binding rulings, their findings can lend moral authority to arguments for certain claims to be accepted as rights.

The 'interpretive standards' (Trask, 2012, p. 334) that the Declaration provides can be used to develop legal arguments and to assist courts and other bodies to interpret instruments of binding effect. In bringing clarity and coherence to the international legal arrangements that indigenous peoples may use to conceptualise and assert their claims, these have the potential to transform the ways that relational justice and just terms of association are understood. It is also significant that, under the Declaration, indigenous peoples enjoy greater opportunity to have an act or omission 
of the state declared a contravention of a fundamental right. For example, in 2016, the Australian Capital Territory's Human Rights Act 2004 was amended to make specific reference to the Declaration:

Aboriginal and Torres Strait Islander peoples hold distinct cultural rights and must not be denied the right-

a. to maintain, control, protect and develop their-

i. cultural heritage and distinctive spiritual practices, observances, beliefs and teachings; and

ii. languages and knowledge; and

iii. kinship ties; and

b. to have their material and economic relationships with the land and waters and other resources with which they have a connection under traditional laws and customs recognised and valued.

Note: The primary source of the rights in [this section] is the United Nations Declaration on the Rights of Indigenous Peoples, art 25 and art 31. (s. 27[2])

Conversely, and significantly, the Human Rights Act confined its reference to just two of the Declaration's articles whereas the full substance of the right to self-determination requires regard for the instrument as a whole. In Canada, this was the purpose of legislation, introduced but defeated in parliament, that would have required all Canadian federal legislation to be consistent with the Declaration ('Bill C-262', 2018 [Canada]). If passed, the legislation could have become a blueprint for the Declaration's implementation, not just in Canada but also in jurisdictions like Australia, New Zealand and the US.

\section{Conclusion}

The Declaration is potentially transformative. While there remain both state and indigenous objections to the principles it establishes (see Chapters 3 and 4), its drafting by indigenous peoples from all parts of the world gives it significant and distinctive political status. The Declaration positions indigenous peoples' collective interests within international human rights discourses and challenges the nature of state sovereignty. Although it is a liberal document, it enunciates a different kind of liberal democracy to that used by postsettler states like Australia, Canada, the US and New Zealand to exclude indigenous peoples from 
substantive and equal citizenship. The Declaration provides a framework for rethinking citizenship, democracy, self-determination and sovereignty. It supports, and is supported by, a liberal theory of indigeneity concerned with just terms of association and political relationships of indigenous agency. However, the Declaration is not a panacea for recognising the right to self-determination. It will not restore indigenous political authority to its precolonial form. Instead, it imagines meaningful indigenous political authority inside the state and beyond it in indigenous institutions operating for indigenous purposes and according to indigenous values.

As the following chapter argues, the Declaration enunciates self-determination as the foundational right from which all other indigenous rights proceed. Chapter 2 shows how self-determination, as normative politics, is a necessary outcome of reconciliation. It also shows the significance of political trust to reconciliation and self-determination. Trust requires the substantive political inclusion that the Declaration intends. 
This text is taken from 'We Are All Here to Stay': Citizenship, Sovereignty and the UN Declaration on the Rights of Indigenous Peoples, by Dominic O'Sullivan, published 2020 by ANU Press, The Australian National University, Canberra, Australia.

doi.org/10.22459/WAAHTS.2020.01 